\title{
Você me dá a sua palavra?: um livro infinito
}

\author{
Can I have your word?: an infinite book
}

\author{
Isabela Magalhães Bosi ${ }^{1}$
}

\begin{abstract}
Resumo:
Neste artigo, buscamos criar um diálogo com a obra Você me dá a sua palavra?, da artista visual Elida Tessler, e refletir acerca da literatura para além de suas formas tradicionais. Nessa obra, Tessler pede a palavra do outro, solicitando que seja grafada em prendedores de roupa. De 2004 até agora, já somam mais de 6 mil palavras, em diferentes línguas. Com esse gesto, a artista desloca a palavra e o objeto de seus usos habituais, compondo um livro infinito, sempre por vir, em consonância com o pensamento de Maurice Blanchot. Ao longo do artigo, convocamos para o diálogo outros pensadores e artistas, como Virginia Woolf, Joan Brossa, Jean-Luc Nancy e Jorge Luis Borges.

Palavras-chave: Elida Tessler. Livro. Palavra.
\end{abstract}

\section{Abstract:}

In this article, we aim to start a dialogue with Elida Tessler's work of art Can I have your word?, and think about literature beyond traditional formats. In this work, Tessler asks the other's word, requesting it to be written on clothespins. Since 2004, it already adds up to more than six thousands, in different languages. With this gesture, she displaces this word and object from their usual uses, creating an infinite book, always to come, as Maurice Blanchot proposes. In this article, we also dialogue with other thinkers and artists, as Virginia

1 Doutoranda em Literatura e Crítica Literária na Pontifícia Universidade Católica de São Paulo (PUC-SP), com Mestrado em Memória Social, na Universidade Federal do Estado do Rio de Janeiro (UNIRIO), e graduação em Jornalismo, na Universidade Federal do Ceará (UFC). 
Woolf, Joan Bossa, Jean-Luc Nancy and Jorge Luis Borges.

Keywords: Elida Tessler. Book. Word.

\section{Quando a palavra não é útil: uma introdução}

A escritora Virginia Woolf, no texto Craftsmanship - um passeio à volta das palavras, assume como ponto de partida de seu pensamento que “as palavras não são úteis" (WOOLF, 2015, p. 2). Ela traz como exemplo a tentativa que fazemos de colocar a palavra a serviço de algo, como na frase "É proibido inclinar-se para fora da janela", inscrita, à época, no vidro de carruagens inglesas (WOOLF, 2015, p. 2). Segundo Woolf, a primeira leitura nos conduz ao significado útil e imediato da frase, mas, num segundo momento, as palavras

mudam, e começamos a dizer "Janelas, sim, janelas - casements opening on the foam of perilous seas in faery lands forlorn." ${ }^{2}$ Sem nos apercebermos já nos inclinámos para fora da janela, à procura de Ruth $^{3}$ num pranto no meio do trigo alheio. A multa são vinte libras ou um pescoço partido. (WOOLF, 2015, p. 2)

A própria palavra, utilizada para proibir alguém de inclinar-se na janela, serviu para conduzir Woolf justamente a fazê-lo, após ser levada pela lembrança da poesia de John Keats, viva na memória da escritora, como ela própria diz: "uma simples frase desperta a imaginação, a memória, o olhar e a audição - tudo isto se combina na sua leitura" (WOOLF, 2015, p. 3). Para Woolf, esse exemplo já “comprova, se é que é preciso haver

2 Woolf se refere a um verso de John Keats, no poema Ode to a Nightingale (Ode a um Rouxinol), que diz: "(Quem sabe o mesmo canto/ Que abriu janelas encantadas ao perigo/ Dos mares maus, em longes solos, desolado.)", traduzido por Augusto de Campos, em Linguaviagem. São Paulo: Companhia das Letras, 1987.

3 Menção a outro verso do poema de John Keats: "(Talvez a mesma voz com que foi consolado/ O coração de Rute, quando, em meio ao pranto,/ Ela colhia em terra alheia o alheio trigo;)". 
prova, que as palavras não nasceram dotadas para a utilidade" (WOOLF, 2015, p. 2).

Segundo a escritora, a natureza das palavras não consiste em "expressar uma afirmação, mas mil possibilidades" e a poesia só existe, portanto, se e quando libertamos as palavras de seus significados utilitários, "que nos permite apanhar o comboio, o significado que nos faz passar no exame" (WOOLF, 2015, p. 6). É esse um dos movimentos da artista visual Elida Tessler em seu word in progress ${ }^{4}$ Você me dá a sua palavra?: libertar e deslocar a palavra de sua função utilitária, puramente comunicacional, por meio de um pedido (que dá nome ao trabalho) e do encontro que acontece quando essa palavra lhe é entregue.

Em seu processo artístico - que parte da relação entre imagem e palavra, transitando da literatura às artes visuais e vice-versa -, Tessler parece estar sempre atenta ao mais ordinário e descartável do cotidiano, recuperando objetos de seus usos comuns para dar-lhes outros sentidos em suas instalações. Esse movimento parte, quase sempre, de um gesto de envio - espontâneo ou não - que gera, muitas vezes, uma correspondência entre a artista e seu interlocutor. Em Você me dá a sua palavra?, o interesse maior é por rastros, alguma memória, na palavra do outro.

Neste artigo, buscamos criar um diálogo com essa obra, compreendida, aqui, também como um livro (im)possível, expandindo a ideia de criação literária para além de suas formas tradicionais. Em consonância com o poeta José Angel Valente, que, no texto A memória do fogo, reconhece a palavra poética justamente no "limite extremo em que se faz impossível o dizer" (VALENTE, 2015, p. 82), no trabalho de Tessler, a potência arma-se precisamente nesse impossível da fala, em que toda palavra perde seu valor usual e se torna poesia.

$4 \quad$ Nas artes visuais, é comum vermos o uso da expressão work in progress para designar um trabalho que não costuma ser exposto pronto ou finalizado, mas que está sempre inacabado, em progresso. Tessler se apropria dessa ideia para criar uma expressão similar para seu trabalho: word in process. Esse jogo de palavras não é aleatório e funciona como uma maneira de reforçar o próprio gesto de Você me dá a sua palavra?. 


\section{Pedir a palavra do outro: um desvio}

Vocême dá a sua palavra? é um trabalho que nasce de um desvio de verbas e verbos. Em 2004, Tessler foi convidada pela Fundação Nacional de Arte, vinculada ao Ministério da Cultura no Brasil, para participar do projeto Oficinas Itinerantes da Rede Nacional de Artes Visuais, que tinha por princípio provocar o deslocamento de diversos artistas brasileiros pelo território nacional. O destino escolhido para ela foi Macapá, capital do Amapá. Antes de iniciar a viagem, a artista sentiu necessidade de adquirir um mapa, palavra que imediatamente formou um desenho sonoro, segundo ela mesma escreve, no texto Você me dá a sua palavra? Do silêncio ao murmúrio utópico do artista (2009):

\section{AMAPÁ \\ O MAPA \\ UMA PÁ}

Ao elaborar essa conexão sonora, que também pode ser lida como um poema, o trabalho conceitual já estava posto: passear pelo Amapá com um mapa e uma pá em mãos. Entretanto, logo ao chegar à cidade, Tessler soube que o então prefeito de Macapá fora preso um dia antes. Diante da tensão política instaurada no local, o evento não pôde acontecer como previsto, tampouco a proposição inicial de Tessler. Durante o caminho para o hotel, a artista formula uma pergunta ao motorista de táxi, interessada em saber por qual razão o prefeito havia sido preso. A resposta, aparentemente banal, foi: "Ele faltou com a palavra!". No dia seguinte, ela se informou de que se tratava de um desvio de verbas. Neste momento, ela assumiu "o desejo de realizar um desvio de verbos" (TESSLER, 2009). 
No mesmo dia, comprou alguns prendedores de roupa de madeira ${ }^{5}$ e deu início ao projeto Você me dá a sua palavra?, um word in process que segue acontecendo sem pretensão de ter um fim, como ela mesma diz: "este trabalho não tem data para ser finalizado, aspirando a um para sempre inerente a quem vive o dia a dia como uma vida inteira." (TESSLER, 2011, p. 12). Desde 2004, a artista passou a pedir às pessoas - amigos ou desconhecidos, nas mais distintas línguas - para escreverem suas palavras num dos prendedores que oferece. A obra, quando apresentada ao público, consiste em uma instalação com fios de arame esticados onde os prendedores são colocados lado a lado, formando, assim, um grande texto, com palavras nas mais diferentes línguas, letras, memórias, mãos.

O filósofo Jean-Luc Nancy, no livro Corpus, elabora o pensamento de que, ao escrever, também nos enviamos. Ele resume: "escrever: o ser que se envia" (NANCY, 2000, p. 20). Com Nancy, podemos compreender a obra de Tessler também como um conjunto de escritas-envios, que parte desse desvio de verbos a que se propôs a artista e se concretiza no gesto de inscrição da palavra do outro em um objeto aparentemente banal. Esse conjunto, sempre incompleto, também pode ser visto como uma coleção, que já acumula mais de 6 mil pregadores-palavras em mais de 15 quilos e, quando colocados lado a lado, somam mais de quarenta metros de comprimento.

5 Uma pequena nota para ressaltar que o prendedor de roupas aparece em outras duas obras de Tessler, anteriores a Você me dá a sua palavra?: em Temporal (1998), elaborado com base na leitura de A Dialética da Duração (1993), de Gaston Bachelard, em que a artista retira do livro as palavras que remetem à passagem do tempo e borda-as em toalhas; e em Coisas de café pequeno (1999), elaborado após a leitura do romance Café pequeno (1995), de Zulmira Ribeiro Tavares, em que Tessler retira do livro todos os substantivos comuns e grava-os em prendedores de roupa, pendurados num varal estendido diante de seis grandes toalhas de banho ( $1,5 \mathrm{~m}$ de largura cada), presas em varais suspensos no teto. Cada toalha remete a um dos seis capítulos do livro. 
Figura 1 - Você me dá a sua palavra?

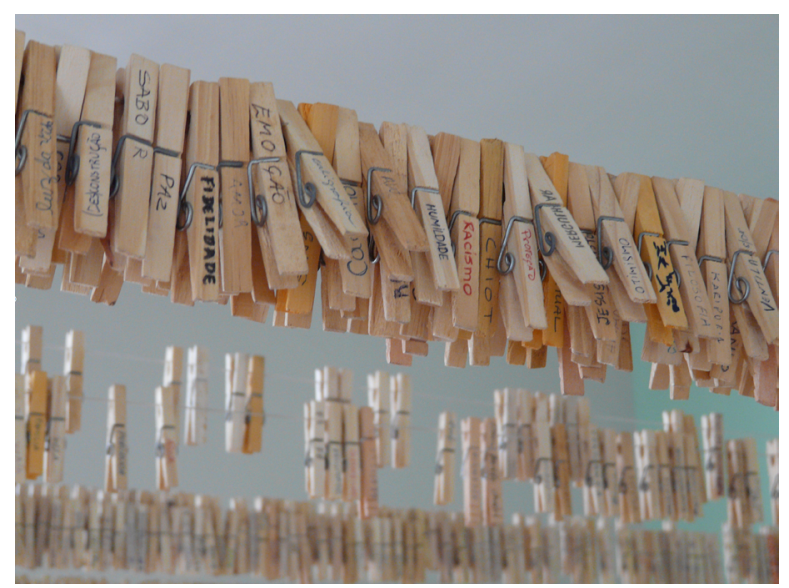

Fonte: Arquivo pessoal de Elida Tessler.

\section{Um livro infinito de palavras únicas}

No artigo Faço minhas as suas palavras: da apropriação à invenção de novos sentidos para a crítica na/da arte, Tessler conta que, desde 2000, dez perguntas norteiam sua pesquisa - tanto no âmbito acadêmico ${ }^{6}$ como nas proposições artísticas:

1) Onde a palavra?

2) Quando a palavra?

3) Como a palavra?

4) Por que a palavra?

5) De quem a palavra?

6) De onde a palavra?

7) Para quem a palavra?

8) Para onde a palavra?

6 Além do trabalho como artista visual, Tessler também construiu uma carreira acadêmica, sendo professora titular e pesquisadora do Departamento de Artes Visuais e do Programa de Pós-Graduação em Artes Visuais do Instituto de Artes da Universidade Federal do Rio Grande do Sul, com extensa pesquisa sobre a relação entre imagem visual e palavra escrita. 
9) Pode ser qualquer palavra?

10) Você me dá a sua palavra?

(TESSLER, 2011, p. 11)

São essas dez perguntas que a estimulam a continuar fazendo o que já faz: "não procurar as respostas, mas configurar distintas maneiras de apresentar estas indagações, tentando buscar dispositivos adequados para apresentá-las a um público mais amplo" (TESSLER, 2011, p. 11). Interessa-lhe, como ela diz, "evocar a palavra como matéria, a palavra como gesto, a palavra como posicionamento e como instrumento de corte" (TESSLER, 2011, p. 11-12). A palavra, então, assume uma possibilidade de cissura, na potência de rompimento com seu sentido primeiro, utilitário, para criação de novos sentidos. Algo como o livro formado por fragmentos de jornal, que o poeta Joan Brossa evoca em seu poema $O$ espelho na pista:

não ia à procura de nenhum tema, senão que aceitava o que lhe acontecia, ainda que fosse em forma de um retalho de jornal: nessa aceitação natural foram-se formando os livros.

criar um sentido em coisas que não o tinham. (BROSSA, 2006, p. 57)

A décima pergunta de Tessler, portanto, sai da lista para dar nome a esse word in process, convocando a palavra a criar outros sentidos em coisas como um prendedor de cabelo. Mais do que simplesmente uma resposta, com a pergunta "Você me dá a sua palavra?", a artista busca um contato por meio do gesto de confiança do outro, como se pudesse se opor, ou até mesmo anular, a falta de palavra do prefeito de Macapá. Ao receber de volta o prendedor grafado à mão, esse objeto tão cotidiano abandona sua função ordinária e assume um novo uso, extraordinário: guardar palavras. 
Assim, em forma de retalho, a artista vai criando novas significações, no gesto que seria, para ela, o sentido da arte: transformar uma coisa em outra (TESSLER, 2009).

Segundo Tessler, "uma pergunta gera outra pergunta" e, na maioria das vezes, ao pedir a palavra do outro, a resposta que ela obtém é outra pergunta: "pode ser qualquer palavra?” (TESSLER, 2009, p. 12). Ela reforça: a sua palavra. O que a artista pede, e espera receber, é uma palavra íntima, que possa dizer algo daquele que a escreve. Pedir ao outro a sua palavra é também uma forma de iniciar uma relação e estabelecer um lugar de confiança, como quem diz "posso me aproximar?", como aponta Adriane Hernandez, no texto Esperança Catavento (2011). Para Hernandez, a palavra entregue a Tessler,

é solta, é livre para ganhar inúmeros sentidos, pendidas na linha-varal do texto que o olhar percorre e caça. Pendurar palavras-dadas, lado a lado, formulando um poema sempre aberto e notável de sentido, mostra-se como uma biblioteca borgiana de infinitas lombadas agrupadas que se percorre como um horizonte (HERNANDEZ, 2011).

Ao pedir a palavra do e ao outro, o trabalho já se estabelece como contato, conversa, uma fala sempre inacabada, que possibilita a formação de um livro infinito, esticado em um varal a formar um horizonte ${ }^{7}$ que nos conduz a outra forma de ler, considerando aquilo que está escrito, onde está escrito e como é escrito.

A cada montagem, as palavras aleatoriamente penduradas no fio de arame formam um longo texto em processo. Uma espécie de livro

7 Faço aqui uma pequena digressão para evocar outro trabalho de Tessler, intitulado Horizonte Provável (2004). Uma instalação criada em homenagem a Haroldo de Campos, para ocupar toda a varanda do Museu de Arte Contemporânea de Niterói. Tessler usa como referência o livro do poeta $A$ arte no horizonte do provável, de qual retira todos os verbos no infinitivo, imprimindo-os em 581 pratos de porcelana branca. Ela dispõe os pratos ao longo das janelas que dão a volta no museu, de frente para o mar, deixando-os próximos à altura do horizonte. Além dos pratos, também imprimiu o livro numa fita de 596 metros, enrolada num tubo de PVC, e, durante a exposição, a esticou ao longo da praia, deixando o livro inteiro aberto, na altura da linha do horizonte. 
fragmentado, escrito por milhares de mãos desconhecidas, em que cada palavra, ainda que repetida, se torna única justamente por carregar o traço e a intenção singular daquele que a escreve. Essa coleção de palavras remete à coleção de areia de Italo Calvino, em que um grão nunca é idêntico a outro e "uma praia de pedrinhas cor-de-rosa nunca é igual a outra praia de pedrinhas cor-de-rosa" (CALVINO, 2010, p. 12). Cada uma - palavra e pedrinha - carrega a memória das mãos, desse momento de contato, de que fala Tessler:

minha convicção é de que cada palavra continua sendo uma pessoa, uma caligrafia, um ponto de vista único, em momento de contato. Se há devolução, esta se caracteriza pela possibilidade de encontro, se não com sua própria palavra, pelo menos com um poema inédito, uma experiência visual e sonora única. ${ }^{8}$

Esse poema único está, a todo tempo, em processo de construção, como um livro por vir, que vai "para além do futuro e não cessa de vir quando está ali”, como diz Maurice Blanchot (2005, p. 352) a respeito da obra de Stéphane Mallarmé, em O livro por vir . Blanchot cita Mallarmé, em uma carta deste a Coppée:

aquilo que devemos visar acima de tudo é que no poema, as palavras - que já são por elas mesmas suficientes, não necessitando receber nenhuma impressão de fora - reflitam-se umas nas outras até parecerem não ter mais sua cor própria, mas serem somente as transições de uma escala musical (MALLARMÉ apud BLANCHOT, 2005, p. 329).

Um longo poema como uma melodia composta por palavras 
que refletem umas às outras, no "movimento silencioso das relações" (BLANCHOT, 2005, p. 346). Palavras que, como escreve a poeta Maria Gabriela Llansol, se reenviam umas às outras, "transformam-se, aparecemme desconhecidas no já antigo conhecimento que eu tenho delas, e o texto toma um alcance de destino" (LLANSOL, 2013, p. 62 Apud FENATI, 2015, p. 110).

Nesse fragmento, escrito por Llansol em 1979, a poeta fala de seu jogo com o dicionário, no qual brinca de reinventar suas possibilidades de uso. As idas de Llansol ao dicionário não tinham como objetivo a busca por sinônimos ou significados, mas, sim, uma procura por rastros da palavra. É nesse jogo inútil e infantil que as palavras podem, enfim, reinventarse. Isso acontece, talvez, porque seu jogo do dicionário "inverte a relação habitual que se tem com ele: parte-se do conhecido ao desconhecido, e não o contrário" (FENATI, 2015, p. 110).

Em Você me dá a sua palavra?, Tessler também cria seu próprio jogo de dicionário, nessa reinvenção dos usos da palavra, que se arma na relação de confiança entre o interlocutor, aquele que envia, e a artista, aquela que recebe, que espera a palavra do outro - e "a obra é a espera da obra" (BLANCHOT, 2005, p. 352). Essa espera, no entanto, se dá em temporalidades distintas que "não cessam de se superpor", em um tempo que pertence a outros tempos (BLANCHOT, 2005, p. 353). Um jogo, portanto, de e com palavras, que se estabelece em diferentes lugares e tempos, formando esse longo poema como um livro inacabado, sem fim, por vir, sempre à espera.

\section{O livro é sempre outro: uma conclusão}

Para Blanchot, todo livro é sempre outro, ideia que também encontramos no escritor Jorge Luis Borges, em seu texto O livro, quando ele diz que um livro sempre muda a cada leitura: "Toda vez que lemos um 
livro, o livro se modificou, a conotação das palavras é outra. Além disso, os livros estão impregnados de passado" (BORGES, 2011, p. 21).

Em Você me dá a sua palavra?, a artista constrói e põe em movimento um livro que, literalmente, é outro a cada leitura, mudando constantemente de conteúdo com o acréscimo de novas palavras, dispostas sempre ao acaso, e com a leitura única de cada pessoa. O livro por vir de Tessler permanece (em) aberto, continuamente "se desdobrando e se redobrando, se dispersando e se unindo", nunca presente e, ao mesmo tempo, não cessando de "se desfazer enquanto se faz" (BLANCHOT, 2005, p. 357).

A artista elabora, junto de seus interlocutores anônimos, esse livro infinito que tem contraditoriamente como fim a própria origem. Ao ver-se diante da falta de verbas, ela começa e termina - sem, de fato, terminar - no desvio de verbos, na busca pela palavra perdida. A primeira foi o motorista de táxi quem lhe deu: amor - até hoje, a mais recorrente no projeto.

De alguma forma, desde a primeira palavra escrita, e a que mais se repete ao longo destes anos, amor, tudo está conectado. Todas as palavras mudam de sentido a cada vez que outra é acrescida, principalmente quando ocorre a repetição; amor amor amor amor amor [...] Em uma mesma linha contínua, encontramos geografias distantes, pessoas que já morreram, crianças que já cresceram (TESSLER, 2009)

Em 2017, treze anos após sua viagem a Macapá, Tessler publicou AMOR:AMOR, um livro-objeto sanfonado que, ao ser esticado, reproduz a ideia da instalação Você me dá a sua palavra?, com uma imagem de 442 prendedores. Neles, lemos a palavra amor, escrita por diferentes mãos, em vários idiomas e caligrafias. Lado a lado, os objetos formam uma linha que pode ser lida também como texto. Apesar da aparente repetição, o que lemos nunca é uma mesma e única palavra, mas uma vastidão de amores 
possíveis. A palavra muda de sentido dependendo de quem a escreveu e de como a lemos. As memórias de cada um interferem na relação com o texto, que também se modifica a cada vez que um novo amor é adicionado a esse livro, que é sempre outro.

Figura 2 - Livro AMOR:AMOR

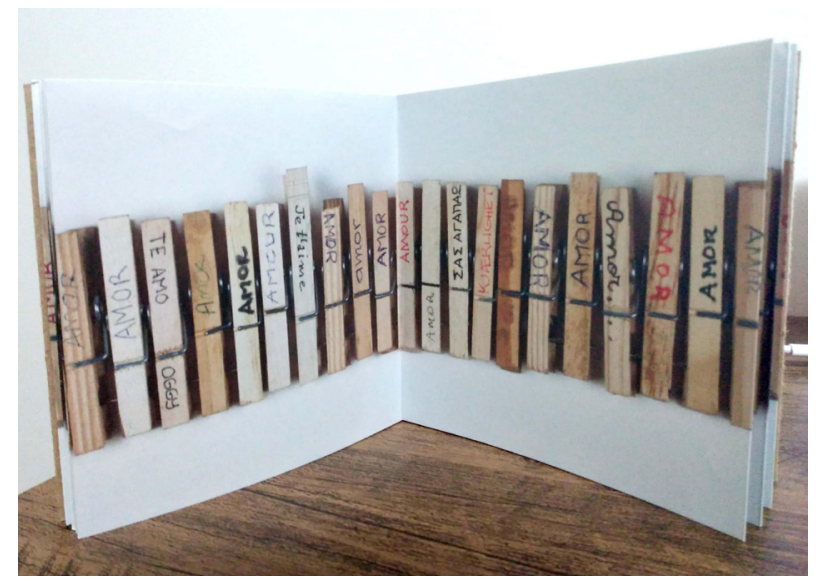

Fonte: Elaboração própria.

Dentro do livro-objeto, em uma espécie de encarte, encontramos os dizeres: "A caligrafia se faz assinatura. O idioma revela origens. A conversa estabelece um ato de criação" (TESSLER, 2017). A ideia de que a palavra escolhida pode ser também assinatura - a marca firmada de uma existência - e de que todo idioma se revela como origem confere à obra uma pluralidade de memórias e sentidos, que cada amor carrega. A conversa como desejo e objetivo é adotada por Tessler como método criativo, não só em Você me dá a sua palavra?, mas em praticamente toda sua obra. É justamente por e para essa disposição ao contato, no gesto de pedir e receber uma palavra, que todo o trabalho se tece. O livro, escrito a muitas mãos, põe-nos diante da inutilidade da palavra, como queria Virginia Woolf. É precisamente nesse lugar que a poesia emerge: quando 
já não há um só sentido ou forma para o amor.

Esse word in process, que se acumula em caixas e mais caixas de prendedores no seu ateliê, é também a forma que a artista encontrou para afirmar que ainda está viva enquanto não morrer, como ela mesma afirma ${ }^{9}$. Nesse movimento de desenvolver um projeto que não termina, vendo-o ganhar corpo ao longo do tempo, a artista permite ao livro uma duração que coincide com sua própria vida, um gesto poético de fazerse permanecer, de viver enquanto não se morre. Em outras palavras: "é poeticamente que o homem permanece" (BLANCHOT, 2005, p. 350).

\section{A minha palavra: quase um apêndice}

No dia em que nos conhecemos, no fim de uma sexta-feira fria em Porto Alegre, perto de nos despedirmos, ela se lembra: "Ah, a sua palavra!". Busca, então, um prendedor de roupa em sua bolsa e uma caneta para me dar, em um gesto que já lhe parece natural, quase involuntário. Vejo-me com aquele objeto pequeno e leve nas mãos, pensando em qual seria a minha palavra naquele momento, a que eu pudesse lhe dar como quem oferece também um pedaço de si, num gesto de confiança, mas, sobretudo, de amor.

\section{Referências}

BLANCHOT, Maurice. O livro por vir. Tradução de Leyla Perrone-Moisés. São Paulo: Martins Fontes, 2005.

BORGES, Jorge Luis. O Livro. Tradução de Heloísa Jahn. In: BORGES, Jorge Luis. Borges oral \& sete noites. São Paulo: Cia das Letras, 2011.

BROSSA, Joan. Sumário astral e outros poemas. Tradução de Ronald Poliro. São Paulo: Amauta Editorial, 2006.

9 Em entrevista cedida a mim, em agosto de 2016. 
CALVINO, Italo. Coleção de areia. Tradução: Maurício de Santana Dias. São Paulo: Companhia das Letras, 2010.

CAMPOS, Augusto de. Linguaviagem. São Paulo: Companhia das Letras, 1987.

FENATI, Maria Carolina. O jogo do dicionário. Gratuita - Chão da Feira, Belo Horizonte, v. 2, p. 106-113, 2015. Disponível em: https://chaodafeira. com/wp-content/uploads/2015/06/Gratuita-vol.-2-Caderno-de-Leituras. pdf Acesso em: 24 ago. 2020.

HERNANDEZ, Ariane. Esperança catavento. In: TESSLER, Elida. Você me dá a sua palavra? [Folder de divulgação da exposição em Pelotas]. Galeria do Centro de Artes da UFPEL, 2011.

LLANSOL, Maria Gabriela. Numerosas Linhas - Livro de Horas III. Lisboa: Assírio e Alvim, 2013.

NANCY, Jean-Luc. Corpus. Tradução de Tomás Maia. Lisboa: Ed. Vega, 2000.

TESSLER, Elida. Você me dá a sua palavra? Do silêncio ao murmúrio utópico do artista. In: 10th INTERNATIONAL CONFERENCE OF THE UTOPIAN STUDIES SOCIETY/EUROPE: FAR OTHER WORLDS AND OTHER SEAS, jul. 2019, Portugal: Universidade do Porto. Disponível em: http://www.elidatessler.com/textos_pdf/textos artista 1/ Voc $\%$ C3\%AA $\% 20 \mathrm{me}^{2} \% 20 \mathrm{~d} \% \mathrm{C} 3 \% \mathrm{~A} 1 \% 20 \mathrm{a} \% 20$ sua $\% 20$ palavra $\% 20-\% 20$ sil $\%$ C3\%AAncio $\% 20 \mathrm{e} \% 20$ murm $\%$ C3\%BArio.pdf Acesso em: 24 ago. 2020.

- Faço minhas as suas palavras: da apropriação à invenção de novos sentidos para a crítica na/da arte. Revista Poiésis, Niterói, n.18, p. 9-14, dez. 2011. Disponível em: https://periodicos.uff. br/poiesis/article/view/27048/15747 Acesso em: 20 ago. 2020. . AMOR:AMOR. Porto Alegre: Azulejo Arte Impressa, 2017.

VALENTE, José Angel. A memória do fogo. Tradução de Gustavo Rubim. Gratuita-Chão da Feira, Belo Horizonte, v. 2, p. 82-85, 2015. Disponível em: https://chaodafeira.com/wp-content/uploads/2015/06/Gratuita-vol.-2Caderno-de-Leituras.pdf Acesso em: 24 ago. 2020.

WOOLF, Virginia. Craftsmanship - um passeio à volta das palavras. Tradução de Cátia Sá. In: Cadernos de Leituras, n. 34, Belo Horizonte: 
Chão da Feira. Disponível em: https://chaodafeira.com/wp-content/ uploads/2015/05/cad34.pdf Acesso em: 24 ago. 2020.

Recebido em: 09/03/20

Aprovado em: 23/06/20 